\title{
Usage of Unreamed Interlocking Nails for the Management of Gustilo Anderson Grade 2 and 3 Open Fractures of Shaft of Tibia - A Prospective Study
}

\author{
Tariq Zaman, ${ }^{1}$ Omer Khalid Farooq, ${ }^{2}$ Faisal Nazeer Hussain ${ }^{3}$
}

\begin{abstract}
Long bones fractures are the main emergency procedures in most trauma centers. Tibial fractures are commonly open as described by the Gustilo classification. Grade III fractures of the tibia (diaphysis) are very challenging injuries. Intramedullary nailing is one of the best known treatments for tibial fractures. It's still being debated which is the most appropriate surgical approach to treat such fractures especially the choice between reamed vs. unreamed nails. This study was designed to determine the outcome of unreamed interlocking nail in open type II and IIIA tibial shaft fractures in terms of infection, bone union, delayed union and nonunion.
\end{abstract}

Patients and Methods: It was a prospective, quasi experimental study, conducted at Department of Orthopedics, Lahore General Hospital/PGMI Lahore upon sixty patients. All subjects with Grade II and III open

\footnotetext{
${ }^{1}$ Medical Officer, Dept of Orthopedics, Attock Hospital

${ }^{2}$ Assistant Profess of Orthopedics

Avicenna Medical College, Lahore

${ }^{3}$ Professor of Orthopedics

Avicenna Medical College, Lahore
}

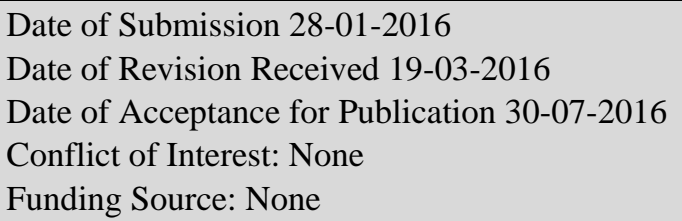

\section{Contribution}

All Authors have contributed in Study Design, Data Collection, Data Analysis, Data Interpretation, Manuscript Writing and Approval. fractures of shaft of tibia were operated using the unreamed nails. They were followed regularly on $3^{\text {rd }}$ then $10^{\text {th }}, 20^{\text {th }}, 30^{\text {th }}$ post-op days. Later a monthly OPD follow up for 9 months was maintained. Records were maintained and analyzed using SPSS 20. Modified Anderson criteria was used to segregate results from poor to excellent.

Results: Mean age of all patients was $32.82 \pm 8.87$ years. Fracture geometry shows that 9 patients had transverse, 27 had oblique, 18 had spiral and 6 patients had comminuted fracture. According to the Gustilo Anderson Classification 43 fractures were Type II and 17 fractures were Type IIIA. Only 9 patients developed infection. Union was seen in $51(85 \%)$ patients and delayed union was observed in 7 (11.66\%) subjects. Two patients $(3.34 \%)$ had nonunion. According to the Modified Anderson grading 47 (78.34\%) patients had excellent, 7 (11.66\%) patients had good and 6 $(10 \%)$ patients had poor results.

Conclusion: On the basis of the results obtained, it was shown that unreamed interlocking nail for treating type II and III A fractures of tibial shaft shows promising and effective results in terms of low rate of infection and bone union. Overall excellent results were seen in $47(78.34 \%)$ patients according to the modified Anderson criteria.

Keywords: Fracture fixation, Interlocking nails, Fractures, Intramedullary, OpenTibial fractures.

\section{Introduction}

Fracture management techniques have evolved over the last century. With increase in high energy trauma open fractures have increased proportionately. Due to their peculiar nature, open fractures of the tibial shaft 
are often managed using POP (plaster of paris) casts, external fixators and concomitant wound care. ${ }^{1}$ There are some problems with external fixation e.g. pin track infection, nonunion, delayed union, malunion, and ankle joint stiffness. ${ }^{2}$ External fixation blocks soft tissues reconstructive procedures due to the placement of pins. Early fixation with interlocking after debridement is now in frequent use for treatment of Type II and IIIA open tibial fracture. It is preferable to fix after early debridement. ${ }^{3}$ Use of unreamed nailing saves the endosteal blood supply, improves fracture healing and decreases chances of infection. ${ }^{4}$ Interlocking nail does not block soft tissue reconstructive procedure giving promising results in treating open type II and III A fractures of tibia. ${ }^{5-8}$ International literature is rife with equivocal opinions regarding use of reamed or unreamed usage of intramedullary devices. It is a known fact now that continuous treatment of fractures with external fixators has its own failures and limitations. ${ }^{9,10,3}$ Our local literature lacks publications on unreamed interlocking nail in the treatment of open type II and III A fractures of tibia.

\section{Patients and Methods}

Sixty patients were admitted through emergency (non probability purposive sampling) Demographic information including age, sex was recorded. All patients were examined and investigated routinely to confirm diagnosis; patients fulfilling inclusion the criteria (Those with open type II and IIIA diaphyseal fractures of tibia presenting within 12 hours of injury, age 18 50 year and of either sex) were included into the study. Patients with malignant disease/pathological fractures, CRF, on chemotherapy and diabetic patients were excluded. Risks were explained, informed and written consent was taken. All procedures were performed by the same surgeon. After thorough debridement under anesthesia, an unreamed interlocking nail was inserted in statically locked mode. All were given IV Ceftrioxone $1 \mathrm{gm}$ twice daily for 1 week beginning at the time of admission and Inj. Amikacin $500 \mathrm{mmg}$ IV 8hourly for 3 - 5 days in contaminated cases. Periodic follow up was done on 3rd then 10th, 20th, 30th post operative day and later at monthly intervals for 9 months in OPD and presence of infection (South Hampton Surgical Infection Scoring, ${ }^{11}$ union, delayed union and nonunion was recorded based upon Hammer et al classification. $^{12}$

\section{Results}

Sixty patients presenting with open type II and III A fractures of tibial shaft were included in the study. Mean age of all patients was $32.82 \pm 8.87$ years. Minimum and maximum age of patients was 18 and 50 years respectively. Forty three patients presented with type - II and 17 patients presented with type - IIIA fracture according to the Gustilo - Anderson classification for open fractures. ${ }^{2}$ Nine $(15 \%)$ patients developed infection. Union was achieved in $51(85 \%)$ of the patients. Delayed union was observed in 7 $(11.66 \%)$ patients and $2(3.34 \%)$ patients had non union. In our study Modified Anderson grading showed that $47(78.34 \%)$ cases had excellent, 7 (11.66\%) had good and $6(10 \%)$ had poor outcome.

\section{Discussion}

Open fractures frequently result in infections, delays in union or lots of subsequent complications. An array of recommendations have been proposed to prevent the complications e.g. early antibiotics administration, radical debridement, immediate fracture stabilization and timely soft tissue coverage. ${ }^{13}$ Opinions are split overthebest choice for skeletal stabilization of the open type III Tibial fractures. A method should be adopted that provides stability, does no damage to the vascularity of the bone and its associated soft tissues. External fixation is known for pin track infections, nonunion, more incidences of reoperation, angular deformities, malunion and poor patient compliance. ${ }^{9,10}$ Despite of a lot of interest the evidence remains equivocal. Intra medullary nailing avoids pin-track infections and offers functionally superior alignment of the limb in the presence of bone loss or comminution. It has been observed that unreamed Interlocking Nails may compromise stability at fracture site. ${ }^{14-17}$ Infection can occur following immediate nailing of Gustilo type III open fractures of the tibia. ${ }^{18-20}$ In order to circumvent this interval intra medullary fixation is delayed for a few weeks after external fixation, however intramedullary infections can still occur. ${ }^{21}$ Daljit Singh treated open type III fractures of tibia with early IMN and found $14 \%$ infection, $14 \%$ non union and $20 \%$ delayed union in his patients. ${ }^{22}$ Advantages of unreamed nails are avoidance of malunion and malrotation, preservation of the endosteal circulation, adequate cosmetic results and easy access for the soft tissue procedures if needed. Fatigue failure and radi- 
ation hazard are the objections to use of IMN. Some authors argue that it is a complicated technique and there is possible higher infection rates in mangled lower limbs. ${ }^{23,20}$ All these drawbacks do not in any way decrease the importance of IMN in open fracture management.

Immediate unreamed interlocking nail for the fixation of open type II and III A tibial fracture offers lower complication rate in our small scale study and it shows promise against an external fixator. An inert metallic implant does not cause infection, but sterile metal in the face of inadequate debridement or absent soft tissue coverage does lead to infection in devitalized soft tissue and bone. Although our study did not use a comparative design the low infection rate and non unions suggest the merits of more studies to be conducted about unreamed nailing in open fractures. The judicious choice of IMN for open type III Tibial fractures provides bone stability of most fractures and with adequate/early soft tissue coverage, leads to favorable results.

\section{Conclusion}

Fixation of open grade II and IIIA fractures of tibia with early unreamed Intra Medullary Nails cause ease in care of the soft tissue injury, lowers infection rates, decreases nonunions. The access to secondary soft tissue and bony procedure is easy.

\section{References}

1. Tielinen L, Lindahl JE and Tukiainen EJ. Acute unreamed intramedullary nailing and soft tissue reconstruction with muscle flaps for the treatment of severe open tibial shaft fractures. Injury, 2007; 38: 906-912.

2. Park H, Uchino M, Nakamura K, Ueno M, Kojima $Y$, Itoman M, Yokoyama K, Suzuki T and Nemoto M. Immediate interlocking nailing versus external fixation followed by delayed interlocking nailing for Gustilo type IIIB open tibial fractures. Journal Of Orthopaedic Surgery - Hong Kong, 2007; 15: 131.

3. Sié HJ, Bamba I, Kodo M and Lambin Y. Primary Unreamed And Unlocked Intramedullary Nailing For Open Tibial Fractures. Nigerian Journal of Orthopaedics And Trauma, 2006; 5: 29-33.

4. Bhandari M, Guyatt G, Emil H, Tornetta P. Randomized trial of reamed and unreamed intramedullary nailing of tibial shaft fractures. J Bone Joint Surg Am, 2008; 90: 2567-2578.

5. Giannoudis P, Papakostidis C and Roberts C. A review of the management of open fractures of the tibia and femur. Journal of Bone and Joint Surgery, British 2006; Volume 88: 281-289.

6. Gustilo RB, Mendoza RM and Williams DN. Problems in the management of type III (severe) open fractures: a new classification of type III open fractures. The Journal of Trauma and Acute Care Surgery, 1984; 24: 742746.

7. Cross WW and Swiontkowski MF. Treatment principles in the management of open fractures. Indian journal of orthopaedics, 2008; 42: 377.

8. Schandelmaier P, Krettek C, Rudolf J, Kohl A, Katz BE and Tscherne H. Superior results of tibial rodding versus external fixation in grade 3B fractures. Clinical orthopaedics and related research, 1997; 342: 164-172.

9. Shannon FJ, Mullett $\mathrm{H}$ and O'rourke K. Unreamed intramedullary nail versus external fixation in grade III open tibial fractures. The Journal of Trauma and Acute Care Surgery, 2002; 52: 650-654.

10. Babhulkar SRH. Open fractures. Ind J Orthop. 2008; 42: 365-367.

11. Pudner, R. Nursing the surgical patient, Elsevier Health Sciences, 2005.

12. Whelan D, Bhandari M, Mckee M, Guyatt G, Kreder, H, Stephen D, Schemitsch E. Interobserver and intraobserver variation in the assessment of the healing of tibial fractures after intramedullary fixation. Journal of Bone and Joint Surgery, British Volume, 2002; 84: 1518.

13. Wheelwright E, Christie J, Mcqueen M. External fixation for type III open tibial fractures. Journal of Bone and Joint Surgery, British Volume, 1990; 72: 801-804.

14. Blick SS, Brumback RJ, Lakatos R, Porn A and Burgess AR. Early prophylactic bone grafting of high energy tibial fractures. Clinical Orthopaedics and Related Research, 1989; 240: 21-41.

15. Caudle RJ, Stern PJ. Severe open fractures of the tibia. The Journal of bone and joint surgery. American volume, 1987; 69: 801-807.

16. Fairbank A, Thomas D, Cunningham B, Curtis M, Jinnah R. Stability of reamed and unreamed intramedullary tibial nails: a biomechanical study. Injury, 1995; 26: 483-485.

17. Trabulsy PP, Kerley SM, Hoffman WY. A prospective study of early soft tissue coverage of grade IIIB tibial fractures. The Journal of Trauma and Acute Care Surgery, 1994; 36: 661-668.

18. Tornetta P, Bergman M, Watnik N, Berkowitz G, Steuer J. Treatment of grade - IIIb open tibial fractures. A prospective randomised comparison of external fixation and non-reamed locked nailing. Journal of Bone and Joint Surgery, British Volume, 1994; 76: 13-19.

19. Trabulsy PP, Kerley SM, Hoffman WY A prospective study of early soft tissue coverage of grade IIIB tibial fractures. The Journal of Trauma and Acute Care Surgery, 1994; 36: 661-668. 
20. Tu YK, Lin CH, Su JI, Hsu DT, Chen RJ. Unreamed interlocking nail versus external fixator for open type III tibia fractures. The Journal of Trauma and Acute Care Surgery, 1995; 39: 361-367.

21. Maurer DJ, Merkow R, Gustilo R. Infection after intramedullary nailing of severe open tibial fractures initially treated with external fixation. The Journal of bone and joint surgery. American volume, 1989; 71: 835.
22. Singh D, Garg R, Bassi J, Singal S. Open grade III fractures of tibia: outcome after early unreamed intramedullary nailing. European Journal of Orthopaedic Surgery and Traumatology, 2011; 21: 321-325.

23. Shannon FJ, Mullett H, O'rourke K. Unreamed intramedullary nail versus external fixation in grade III open tibial fractures. The Journal of Trauma and Acute Care Surgery, 2002; 52: 650-654. 